\title{
Business Intelligence in Healthcare Organizations
}

\author{
Ton A.M. Spil \\ University of Twente \\ a.a.m.spil@sms.utwente.nl
}

\author{
Robert A. Stegwee \\ University of Twente \\ r.a.stegwee@sms.utwente.nl
}

\author{
Christian J.A. Teitink \\ Cteitink@hotmail.com
}

\begin{abstract}
The management of healthcare organizations starts to recognize the relevance of the definition of care products in relation to management information. In the turmoil between costs, care-results and patient satisfaction the right balance is needed and can be found in upcoming information and communication technology. The ICT developments are a challenge in two directions, inside toward massive Data warehouses, outside toward internet dissemination. These new technologies deliver new solutions for old problems. This paper argues that although the new technology has a high potential, a great deal of the solution will be of an organizational nature. In four cases we show the spectrum from organizational solutions (changing structure and definitions, forms and procedures), to ICT solutions (changing systems and infrastructures).Main results of this study were the notion that model bases, although in theory existent for more than two decades are still scarce in healthcare organizations. Secondl, a big gap, both on content and on price, was noticed between decision oriented and model oriented systems. Finally the definition of terminology and the standardization were time consuming tasks on the road to management information in the four cases studied. Business Intelligence can be the integration between the organizational and ICT component by using a management model and a concept of integrated systems. The use of intranet and internet as communication channels for management information is seen as the challenge for the near future.
\end{abstract}

\section{Introduction}

The delivery of healthcare has always been information intensive, and there are signs that the industry is recognizing the increasing importance of information processing in the new managed care environment (Morrisey, 1995).
As a result of societal trends towards a more businesslike attitude regarding government and not-for-profit services, the management of healthcare institutions in the Netherlands is changing focus. Having concentrated on financial issues, the developments in medical technology and the aging of the population have broadened the attention to include process and outcome variables as well. Both qualitative and quantitative indicators for the actual performance of healthcare institutions, in relation to the expenses incurred, are being proposed. The notions of 'value for money' and transparency of the expenses in healthcare now dominate the external frame of reference. All parties involved have realized that, in order to respond to these reporting requirements, some kind of product definitions have to be developed. Well established ways of doing this, like diagnosis related groups (DRGs), have been dismissed as being too much focused on inpatient care and having no direct medical relevance. It has proved difficult to come up with alternatives, as healthcare institutions and professionals tend to personalize the cure and care processes for the individual patient. The complexity of the organization with its many different professional groups and the number of distinct patient groups makes it hard to define the products of healthcare institutions. Moreover, professionals will have to buy into the product definitions in order to have an impact on the actual process and quality management within the organization. Such a commitment is often hard to come by, especially when reporting is considered primarily a financial issue with a tendency to result in budget cuts rather than to foster better cooperation and quality of care. Finally, most healthcare institutions lack the appropriate information systems to produce reliable reports with respect to other information than purely financial and volume related statements (Prins \& Stegwee, 2000).

With the introduction of DRG's the providers will have very strong incentives to continually 
monitor care outcomes and streamline care delivery ((Bartling, 1995). In short, the importance of decision support in the delivery of managed healthcare can hardly be overemphasized (Hampshire \& Rosborough, 1993). A variety of decision support capabilities will be necessary to increase the productivity of medical personnel, analyze care outcomes, and continually refine care delivery processes to remain profitable while holding the line on costs and maintaining quality of care (Dutta \& Heda, 2000). Healthcare decision support is faced with the challenges of complex and diverse data and knowledge forms and tasks (Prins \& Stegwee, 2000, Sheng, 2000), the lack of standardized terminology compared to basic sciences, the stringent performance and accuracy requirements and the prevalence of legacy systems (Sheng, 2000).

This paper reports a study on different ways in which healthcare institutions have tackled the development of information systems for a broader range of reporting than the traditional financially oriented information. To this end we first introduce a number of basic notions with respect to management information in healthcare institutions. Secondly, we provide an overview of different business intelligence tools that may be appropriate in the development of a computer based management information system. This rather theoretical discussion will be followed by the presentation of four case studies. The first case only shows organizational solutions and administrative solutions. The second case shows a combination of spreadsheets and organizational changes. The third case relates to the development of a Data warehouse within a hospital. The last and fourth case shows the implementation of a big management information system specially made for healthcare.

\section{Management Information in Healthcare}

Management information in healthcare institutions in the Netherlands has been limited to such figures as number of procedures performed per specialist, percentage of occupation of hospital beds, average duration of stay in the hospital, number of first visits by outpatients per specialist, and the cost of care broken down into a number of cost categories. A study on hospital desires with respect to management information uncovered very different needs: an identification of major patient groups and statistics on the respective resource usage and quality outcomes for these groups and on the process timing characteristics like waiting times, throughput times etc. A future wish concerns the monitoring of the healthcare process across organizational boundaries. More or less in line with these developments a project has started to define so-called diagnosis-treatmentcombinations (called DBC's in Dutch), which provide for easy identification of the particular group a patient belongs to. The government intends to establish new rules for reimbursement of hospitals and medical specialists based on the definitions of these DBC's. It is clear that such information requires information from a variety of sources, which has to be combined in intelligent ways.

To show some of the complexity of this process, consider the following fairly typical situation in a Dutch hospital. The patient's diagnosis is only recorded in the paper-based medical record of the specialist. For inpatients this information is coded using ICD-9 by the medical records department in order to provide input to the National Medical Register. The procedures performed on the patient are recorded by different ancillary information systems and sent to the central billing system for processing. However, the rules that apply to billing do not cover all the procedures performed, which means no procedure codes are available for recording these events. Some hospitals have introduced special codes, alongside the official procedure codes for billing, to accommodate the non-billable procedures of interest within the reporting system. Others may have to resort to the ancillary systems to access this information. The actual visits to outpatient clinics and the hospital are recorded in the hospital information system, but they are often not linked to the procedures carried out, nor do they always lead to billable items in the billing system. Outcomes of treatments are sometimes recorded by medical specialists as input for a national register maintained by their professional society. This is usually done by means of a stand-alone PC-based system, from which periodically files are uploaded to a national system. As such, the hospital often does not have access to these outcomes management systems.

It is clear that the ultimate form of management information can not be based upon the current situation with respect to data recording. Some of the necessary links in the 
underlying data are missing. However, given some simplifications of the DBC definitions, hospitals have been busy trying to uncover as much information as possible. Even though the above discussion has focused mainly on hospitals, other healthcare institutions are faced with similar problems. However, due to their size and the dynamics of their particular patient groups, different solutions might apply to the smaller and more care-oriented institutions.

\section{Business Intelligence Tools}

Most automated systems are used as a tool for daily work: they are focused on 'production' (daily registration). All the data, which are used to keep the organization running, operational data, are in these automated systems. These systems are also called legacy systems.

There is a growing need to do more with the data of an organization than to use them for administration only. A lot of information is hidden in the legacy systems. This information can easily be extracted. Most of the times this can not be done directly from the legacy systems, because these are not build to answer questions that are unpredictable. Because of this, the data first will be transferred to a socalled Data warehouse.

The concept of a data warehouse (Berndt et al., 1999) allows a core set of reports to be produced at a reasonable cost for community use. In addition, Business Intelligence tools can be used to gain a deeper understanding of the health care issues. A data warehouse can be constructed, for enabling both cost-effective report generation and ad-hoc analyses of critical health care issues. The construction of a data warehouse for public health care data poses major challenges beyond that required for the construction of a commercial data warehouse. Such challenges include:

- Data come from a diverse set of sources. There are currently few standards in the health care field for data.

- Reports are disseminated to a diverse and geographical distributed set of stakeholders.

- The data warehouse concept is required to support the activities of public policy formulation.

The human-computer interface is of paramount importance in the data warehouse environment and the primary determinant of success from the end-user perspective. In order to support analysis and reporting tasks, the data warehouse must have high quality data and make that data accessible through intuitive interface technologies. One can discern a number of different types of users of a data warehouse. Firstly, there are users that just want to access the standard reports issued by the data warehouse, probably as part of the regular reporting cycles within the organization. Secondly, users may want to make a further analysis of the underlying data presented in the reports. Such users should be able to search for underlying causes of irregular developments showing up in the reports. A final set of users can be identified when we consider business analysts who use the reporting data as input to models to analyze trends and to anticipate the impact of possible alternative decisions or developments. These three user-groups obviously will have different requirements with respect to the interface with the data warehouse technology.

Another way to look at information systems supporting the users of management information comes from the cases to be discussed later on. It basically concerns itself with the type of technology employed. The most basic system is a paper based system, for which procedures have been implemented in the organization to ensure the proper recording, processing and reporting of the relevant data. A bit more advanced is the use of spreadsheet models to automate part of the processing and reporting process. A data warehouse, in combination with business intelligence tools, as discussed above, can be seen as an automated data collection process with flexible processing and reporting functions. Finally, a full-blown Management Information System (MIS) differs from a data warehouse in the sense that it usually performs extensive processing on the data uploaded to the MIS before storing the data. The MIS is typically designed from an explicit perspective on the control mechanisms within the organization and the reports necessary to support these controls. As such it preprocesses the raw data to fit the control model of the organization.

In combination these views lead us to the following options for information systems supporting different users in a healthcare environment.

In the next section we will examine the usefulness of business intelligence tools with respect to the different types of users and the ways in which the data is gathered and stored. 
To make reports and analysis out of the data in a Data warehouse must be easy. This means that people can concentrate themselves completely on their jobs without being busy with the technical infrastructure of a Data warehouse. Tools are available, that can make that possible. Those tools are called Business Intelligence (BI) tools. In this paragraph a global, functional classification of BI tools will be described.

\section{Functional classification of BI tools}

In IT literature a lot is said about Information Warehouses and available BI tools. The purpose of this résumé is a quick reference of BI tools on the market. Below a classification of BI tools on functional criteria is shown based upon the work of Alter (1977) in the late seventies.

\section{Data oriented tools}

In this group are the tools that are complete Structured Query Language (SQL)-oriented and the File Drawer "tools". These provide a flexible ad-hoc query capability for the more advanced user. This basic access mechanism is a standard relational database access path, but requires some care in the data warehouse environment. Very large tables and ill-formed queries can conspire to produce some truly awful performance. (Berndt et al, 1999) That is the reason that the end-user in some cases has to have knowledge of both the relational structure of the databases and tables and SQL language.

A further division can be made in:

- File Drawer systems

These are the simplest DSS, yet they can often be of value (Mallach, 1994). Executive IS tools are tools that are close to the database structure. It must be possible for users to create queries themselves. In most of the cases queries are made by specialists (experts at the end-user organization or at the IT department). End-users use these queries by defining variables, for example: period, department or geographic region. These systems do not have to be automated but most of the time do allow immediate access to data items.

- Database query tools

Database query tools give more possibilities to the end-user in asking questions at the database management system (the database). However these tools are strongly SQLdirected. In this group a further division can be made in simple and extended interactive query tools. This group forms a combination between data analysis and analysis IS (Alter, 1977).

\section{Decision oriented tools}

Decision support tools (DSS) give the endusers more possibilities to approach and to use data-collections. End-users can turn data into information. This information will be analyzed and turned into knowledge. Queries that are used are completely different from the ones that are used by SQL oriented tools. DSS tools can be classified in two subgroups:

- Spreadsheets

Spreadsheets provide mainly functionality's in the area of reports and statistical operations. There is a main difference between financial and general spreadsheets where the financial ones are much more restricted in use. Other tools combine spreadsheets with their own software.

- Online Analytical Processing (OLAP)

On-Line Analytical Processing (OLAP) is a category of software technology that enables analysts, managers and executives to gain insight into data through fast, consistent, interactive access to a wide variety of possible views of information that has been transformed from raw data to reflect the real dimensionality of the enterprise as understood by the user. OLAP is implemented in a multi-user client/server mode and offers consistently rapid response to queries, regardless of database size and complexity. OLAP helps the user synthesize enterprise information through comparative, personalized viewing, as well as through analysis of historical and projected data in various "what-if" data model scenarios. This is achieved through use of an OLAP Server.

\section{Model oriented tools}

Datamining is the search for characteristic patterns or regularity in the database. For an end-user searching for regularity is important, because in advance the end-user does not know what he is looking for. For example: searching for risk-profiles is searching for a characteristic description of accident-prone persons. A distinction is drawn between the use as exploratory or confirmatory methods, but the results are a model or set of abstract 
patterns that can be applied to other data sets. (Berndt et al, 1999) Below a classification of tools is made upon technical solutions.

An example of datamining in the healthcare environment was described by Houweling (2000). By using a datamining model a prognoses could be made for nausea before and after an operation. Alter (1977) defined these systems as suggestion and optimization systems. We classify the model oriented tools in four categories:

- Neural Networks

Neural Networks are networkarchitectures that 'learn' how problems have to be solved.

- Induction
Induction is the distraction of information by generalizing from within the database.

- Statistics

The end-user will have to take more actions with this method. The end-user himself describes the model, which the computer uses to analyze the data

- Visualization

This technique combines the data with dimensions. There is no analysis on the computer (besides the base functionality's). The analysis will be performed by the enduser himself, behind the screen.

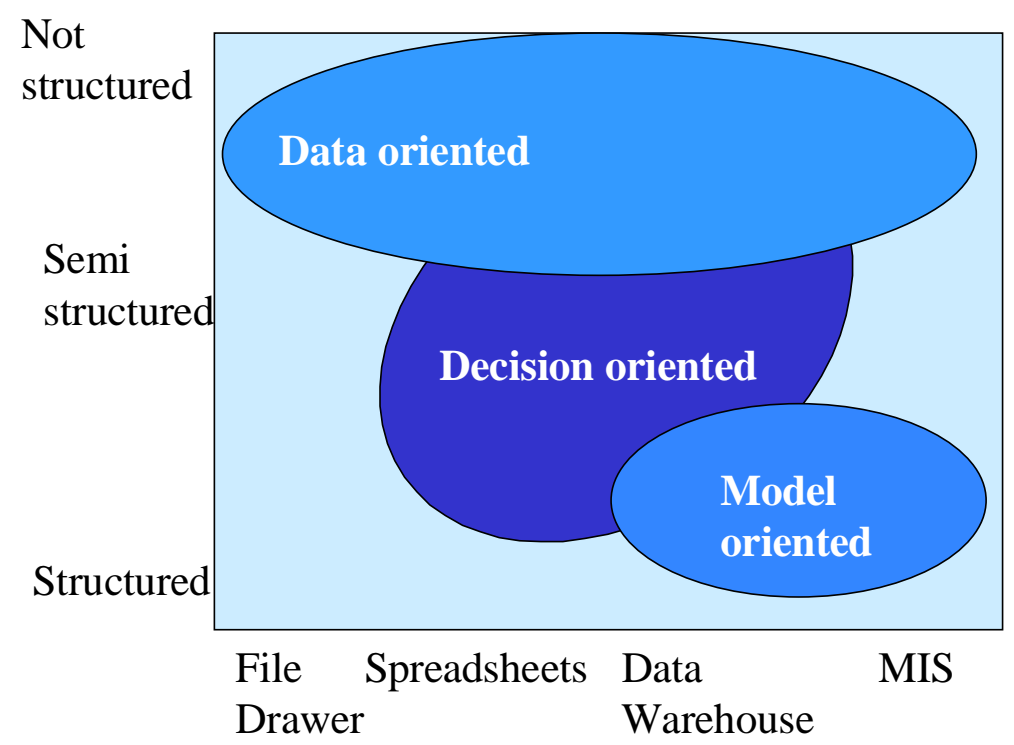

Figure 1-Case framework relations

\section{Case studies}

In this chapter, four cases are described of healthcare organization that solved their managed care problems in totally different ways with different Business Intelligence tools. In table 1 a summary of the results is given. The organizations are compared in size and level of ICT adoption (Cash et al, 1994). The systems used in the cases are compared on scalability, shifting needs and user acceptance (Sheng, 2000). To put them financially into perspective we estimated the perceived value for money by looking at the costs of the system and the perceived value by the users. To see whether the applications in the cases are data or model oriented we compared them with Alter's (1977) model. Finally we looked whether they could be used just on a regular standard output or an ad hoc specific output
(Mallach, 1994). The case summary is not repeated in the text description. For the extensive case descriptions we thank the authors (Hoele 94, Rutgers, 97, Ekkelenkamp, 99, Sikkel et al.,99 \& Paardekoper, 2000). The authors of this paper were involved in all cases except case three that was assessed from the information we got from the website (LUMC, 2001). In the near future we start an action study on OLAP at Medinet-1 to be a substitute for case three. The cases must be seen as illustrations of the theory listed above and not as evidence. The scales are ordinal and relative between the cases and should be seen as qualitative indicators. 


\begin{tabular}{||l|l|l|l|l||}
\hline \hline & $\begin{array}{l}\text { CASE 1 - FILE } \\
\text { DRAWER }\end{array}$ & $\begin{array}{l}\text { CASE 2 - } \\
\text { SPREADSHEET }\end{array}$ & $\begin{array}{l}\text { CASE 3 - } \\
\text { DATAWARE- } \\
\text { HOUSE }\end{array}$ & CASE 4 - MIS \\
\hline Size (\#beds) & 77 & 530 & 867 & 1100 \\
\hline ICT adoption & Low & Average & High & High \\
\hline Scalability & Average & Average & High & Average \\
\hline Shifting needs & Average & Average & High & Low \\
\hline User acceptance & High & Average & High & Average \\
\hline Perceived value & High & High & Low & Low \\
\hline Data oriented & High & High & High & High \\
\hline Decision oriented & Low & High & High & Average \\
\hline Model oriented & Low & Average & Average & High \\
\hline Ad hoc query & Low & Low & High & Average \\
\hline Regular reports & High & High & High & High \\
\hline \hline
\end{tabular}

Table 2 - Summary of case results

\section{Case 1-File Drawer in a Clinic}

\section{BACKGROUND}

Case one is a clinic for addicts of alcohol, drugs, gambling and medicines. It has $100 \mathrm{fte}$ capacity, 77 beds and 10 "chairs". It was part of a psychiatric institute and the privatization brought many changes to the organization. The complexity of the organization has grown and the number of treatment departments have grown. All supportive departments are new. The result was that there was a need for management information.

\section{OUTCOMES}

As a result of a preliminary study, four alternatives were proposed for delivering the management information:

- Generate management reports by hand;

- On-line information gathering from databases;

- Create an extra information layer;

- Build an integrated system.

In this case the choice was made for a handmade report. This means that the information needed is gathered from different systems and is put together in a presentation system. There is no direct line between data gathering and information presentation.

The choice was made upon two main reasons. The clinic did not have access (enforced by law) to one of the databases (personnel) that was a main source of information and the clinic did not have a high level of skills on information management.

\section{KEY CONCLUSIONS}

Situational aspects like law enforcements have to be taken into account when choosing a new BI system.

The size of the organization is relatively small which can have a big influence on the choice of a system.

The level of ICT adoption influenced the choice of the Business Intelligence system in this case.

\section{Case 2-Spreadsheets in a hospital \\ BACKGROUND}

The regional hospital has 2350 fte capacity and 530 beds. All important specialization's are represented in the institute. The regional hospital had a lack of planning on tactical level in the organization. What also lacked was the integration of the planning on operational level. This means that there was no communication between departments on activity plans and implementations. Another problem is that when exceptions are noticed by the financial administration that they do not have the authority and measures to change the organization.

\section{OUTCOMES}

The planning cycle and levels of planning were changed in the hospital. Especially the integration of the operational planning was improved. There was too much detail in the spreadsheets that management received and therefore summaries were made and these summaries were delivered to the managers on different levels as a front-page with the 
detailed data behind it. The front pages are structured by department and by medical specialist.

\section{KEY CONCLUSIONS}

An information system seldom is the main solution to a problem. The organizational changes made in this case are much more important than the information system (spreadsheet) used. Another key conclusion is that in counter of the management information there was a need for change of control measures in the organization studied.

In this case the possibilities of the information system were much higher than used by management of the organization. By making better use of existing systems, the organization could improve its management.

An optional conclusion from this case is that there is a big gap between (relatively simple) spreadsheet solutions and on-line data warehouse solutions. This gap contains a big price difference but also a large infrastructural difference.

\section{Case 3-OLAP in an academical hospital}

\section{BACKGROUND}

The academical hospital has a $3600 \mathrm{fte}$ capacity and 867 beds. In the hospital information system all basis information about patients and personnel is registered. The budgets of academical hospitals have become tight and therefore the academical hospital in this case was searching for a way to use their resources optimally. To determine these optimal situations, management of the organization demanded more detail information about their department. Especially, information was needed on waiting lists, bed occupation, origin of patients and level of service.

\section{OUTCOMES}

The academical hospital has started to build a database on which it could generate reports on standard user questions, using spreadsheets and a presentation layer. After three years, the borders of the spreadsheet system were reached and therefore the choice was made for a new presentation layer OLAP and a better datastructure in the form of a data warehouse. From existing and known questions, multidimensional cubicles were made and new functions were added. About 75 people in the organization are at this moment able to use the system.

\section{KEY CONCLUSIONS}

By using this data warehouse the flexibility of the system was improved and the costs of management information systems was decreased (control and maintenance).

The evolution of the management information system in this case clearly reads as a learning process. The organization went through a spreadsheet learning phase and derived at a new phase with its data warehouse.

\section{Case 4-A MIS at a general hospital BACKGROUND}

The general hospital has a 3000fte capacity and more then 1100 beds. The management of the hospital is highly decentralized. To answer problems in the cost price allocation, budgeting and planning in general a management information system was sought.

\section{OUTCOMES}

The dedicated MIS makes a distinction in financial/economical steering and medical management decisions and delivers three levels of analysis. On the first level the resources are allocated and used in half products (e.g. a labresult or a nurse hour). On the second level the half products are used to reach the end product, a treated patient. On the third level these patients can be grouped in care units.

To implement the system in the organization four steps were used: Budget management, Treatment management, Care unit management and Integral management. Each deliverable was meant for different management groups in the organization.

\section{KEY CONCLUSIONS}

The costs of the chosen management information system were rather high but it generated a dedicated system with a high potential of management information.

The project structure of the implementation group proved to be important because changes were made throughout the organization. The deliverables were split up in functionality's (modules).

The chosen MIS was made in the United States and financially oriented. It proved to be difficult to use the same system in a different culture. 


\section{Conclusions and further research}

In theory model bases exist since the seventies but in practice and in particular in the case practices we did not find these model bases. The MIS and Data warehouse have tools to build suggestion systems but the use of them is very limited.

In all cases the technological changes appeared next to organizational changes. The new technology push delivered new possibilities for old problems but the systems have to be embedded in a procedure or structure to be truly effective.

The choice of systems seems to be most dependent on two determinants, size and level of ICT adoption and organizational learning. The organizations need the financial resources to be able to bridge the gap between spreadsheets and data warehouses and need the knowledge resources (personnel) to bridge the same gap as regards content. From these four cases we tend to state that the gap between decision oriented systems and model oriented systems is quit big in the healthcare environment.

In all cases defining the information requirements was a difficult and time consuming job. For instance the term bed could mean as much as snow for an Eskimo. Definition of terminology and standardization are important constraints for management information in healthcare organizations.

Only in the academical hospital the first signs of Intranet use in combination with the Data warehouse were seen. Further research on the Intranet and Internet in combination with Business Intelligence is necessary to predict the future management communication. We think that in the near future most management information will be made available through the Intranet of the healthcare organization.

Spreadsheet solutions do not always provide the manager with the right insight. Other multidimensional tools are more flexible and more powerful. Yet, the perceived value for money seems much better than OLAP or MIS solutions. It can be expected that the development of data warehouses as an impact of the need for integrated management information will get a big impulse in the coming years. To envision care products in content and clinical results data warehouses will be essential. From these four cases the question for further research can be: "Where is the break even point for building a data warehouse"? Clearly the answer should not only be sought in money but also in the level of ICT adoption. Also the integration of models in the OLAP solutions can be a concern.

\section{References}

Alter, S (1977) "A classification of decision support systems" Sloan Management Review,19,1, pp95-116.

Bartling, AC (1995)'"Trends in Managed Care", Healthcare executive, 10, 2, pp6-11.

Benbassat, I \& Schroeder, R G (1977), “An experimental investigation of some MIS design variables" MIS Quarterly, 1, 1, march, pp37-49.

Berndt, D J, Hevner, A R \& Studnicki, J (1999)"Community Health Assessments; a Data Warehousing Approach" Proceedings of European conference on Information Systems, Vienna.

Butters, S \& Ecom, S (1992)"Decision Support Systems in the healthcare industry", Journal of Systems Management, 43, 6, pp28-31.

Cash, J I, Eccles, R G, Nohria, N \& Nolan, R $\mathrm{L}$ (1994)Building the information age organization:Structure, Control and Information Technologies, Irwin, Boston.

Dutta, A, Heda, S (2000)" Information systems architecture to support managed care business process", Decision Support Systems, 30, pp 217-225.

Ekkelenkamp, J (1999)Besturen onder invloed, (In Dutch), Doctoral Thesis Technology \& Management, University of Twente.

Galliers, R D, Pattison, E M \& Reponen, T (1993)"Strategic information systems planning workshops: lessons from three cases" International Journal of Information Management.

Gibson, C, Chaves, C, Wilkes, R B \& Frolick, M N (1994)" Management support systems at Promus"Information Systems Management, 11, 3 summer, pp 51-56.

Gorry, G A \& Scott Morton, M S (1989)"a Framework for management information systems", Sloan Management Review, 30, 3, spring, pp49-61. 
Hampshire, D A \& Rosborough, B J (1993)"The evolution of decision support in a manged care organization", Topics in healthcare financing, 20, 2, pp26-37.

Hoelen, A J (1994)Transition 1 en de implementatie bij Medisch Spectrum Twente (In Dutch), Nabla advies, NBL4006, Leimuiden.

Houweling, P L (2000)'Dilemma's bij complicatieregistratie" (in Dutch)Nederlands tijdschrift voor Medische Administratie

LUMC(2001)http://www.cognos.com/compan y/success/leids.html

Mallach, E G (1994)Understanding Decision Support Systems and Expert Systems, Irwin, Chicago.

McMahon L F, Eward A M, Bernard R A \& Hayward, R A(1994)'"The integrated inpatient management model's clinical management information system"Hospital and Health Services Administration, 39, 1, pp81-92.

Murtaza, A H (1998)"A framework for developing enterprise data warehouses", Information Systems Management, 15, 4, fall, pp 21-26.

Morrisey, J (1995)"Managed care steers info systems, Modern Healthcare, 25, 8.

Paardekoper, C L (2000)Methoden voor het bepalen van relevante managementinformatie (In Dutch), Doctoral Thesis Technology \& Management, University of Twente.

Prins, S \& Stegwee, R A

(2000)'ZZorgproducten en geintegreerde infromatiesystemen", (in Dutch) Handboek sturen met zorgproducten, F3100-3, december.

Rutgers, H M (1997)Het Onze Lieve Vrouwe Gasthuis op weg naar een beter beheersbare situatie, (In Dutch), Doctoral Thesis

Technology \& Management, University of Twente.

Scheese, R (1998) “CPA, Data warehouseing as a healthcare business solution, Healthcare Finanacial Management.

Sheng, O R Liu (2000)"Decision support for healthcare in a new information age", Decision Support Systems, 30, pp101-103.
Sikkel, K, Spil T A M \& Weg, R L W van de (1999)"A real world case in Information technology for undergraduate students, Journal of systems and software,49, 2-3, December.

Spil, T A M \& Stegwee R A (2001)"Strategies for Healthcare Information Systems", IN Stegwee, R A \& Spil T A M (eds.) Strategies for Healthcare Information Systems, IDEA Group publishing, Hershey. 